Int. J. Electrochem. Sci., 15 (2020) $8883-8891$

\title{
Detection of Ofloxacin by Differential Pulse Voltammetry in Drugs Based on a Novel p-Aminobenzene Sulfonic Acid/Graphene Electrochemical Sensor
}

\author{
Xiaojing Si ${ }^{1}$, Chen Bai ${ }^{1}$, Xia Gong ${ }^{1}$, Jingting Han ${ }^{1}$, Zichao Chen ${ }^{2 *}$, Yaping Ding ${ }^{3, *}$ \\ ${ }^{1}$ Department of Food Science, Shanghai Business School, Shanghai, 200235, PR China; \\ ${ }^{2}$ Experimental Center, Shandong University of Traditional Chinese Medicine, Jinan, 250355, PR \\ China; \\ ${ }^{3}$ Department of Chemistry, Shanghai University, Shanghai, 200444, PR China \\ *E-mail: wdingyp@sina.com
}

doi: $10.20964 / 2020.07 .46$

Received: 4 March 2020 / Accepted: 27 April 2020 / Published: 10 August 2020

This work demonstrates fabrication and performance (towards ofloxacin (OFL) detection) of a unique electrochemical sensor, composed of p-aminobenzene sulfonic acid (ASBA) and grapheme (GR). For this purpose, a glassy carbon electrode (GCE) was coated by GR using electrochemical deposition and then electro-polymerized by ABSA. The surface and morphology of the resulting composite pABSA/GR/GCE were analyzed using scanning electron microscopy. Oxidation peak currents obtained from the differential pulse voltammograms with the assistance of the composite $\mathrm{pASBA} / \mathrm{GR} / \mathrm{GCE}$ showed linear correlation to the OFL concentrations in the $0.1-40 \mu \mathrm{mol} / \mathrm{L}$ range with the detection limits of acetaminophen is $0.03 \mu \mathrm{mol} / \mathrm{L}(\mathrm{S} / \mathrm{N}=3)$. We also demonstrated OFL detection using pASBA/GR/GCE in pharmaceutical formulations. These results indicate that pASBA/GR/GCE has very strong potential as an electro-analytical sensor for the detection of components in pharmaceutical formulations.

Keywords: Differential Pulse Voltammetry Determination; Modified electrode; Graphene; paminobenzene sulfonic acid; Ofloxacin

\section{$\underline{\text { FULL TEXT }}$}

(C) 2020 The Authors. Published by ESG (www.electrochemsci.org). This article is an open access article distributed under the terms and conditions of the Creative Commons Attribution license (http://creativecommons.org/licenses/by/4.0/). 